\title{
E-customized Product: User-centered Co-design Experiences
}

\author{
Pei $\mathrm{Li}^{1}, \mathrm{Zi}$ Yang $\mathrm{Li}^{2 *}$ \\ ${ }^{1}$ School of Textiles and Fashion, Shanghai University of Engineering Science, \\ Shanghai, P.R.China \\ [e-mail: pacywu@ 126.com] \\ ${ }^{2}$ Kyonggi University \\ Suwon-si, Gyeonggi-do, 16227, Republic of Korea \\ [e-mail: morninglzy@ hotmail.com] \\ *Corresponding author: Zi Yang Liu
}

Received January 27, 2020; revised March 23, 2020; accepted May 7, 2020;

published September 30, 2020

\begin{abstract}
The purpose of this study is to orient users' touchpoints in co-design experience, to identify their need via visualized experience map, to recommend valid design information in online e-customization services. A user-centered co-design experience map (UCEM) is adopted to analyze the relation between users' desire and time spent, so as to evaluate the online co-design experiences. Based on evolutionary algorithm and fuzzy theory, data of this study is collected from 30 participants. The data was analyzed by descriptive analysis in SPSS, and frequency query and word cloud in NVivo. Employing design category and evaluating users' time spent, the findings are that (a) vamp color matching is consistent with interview data; (b) supported by qualitative feedback, the virtual experience map played an important role in the co-design process and the visualized interaction process; and (c) participants prefer to get more information and professional help on color matching and exterior design. Based on the findings in design category, future work should be focused on developing a better understanding of design resource recommendations and multi-stakeholder communication.
\end{abstract}

Keywords: Co-design, Process, Problem Solving, User Experience 


\section{Introduction}

A mong a wide range of product recommending systems, it is increasingly acknowledged that the e-customized co-design system is coming. The co-designing process of e-customizable brands not only contributes to reduced product stocking but also helps deliver effective design to consumers and enhances satisfaction for new customized products [1]. Since co-design is applied to brands, consumers benefit from reduced time spent on visiting retail stores. From a theoretical view, an e-customized co-design system positively influences consumer behavior. First, in line with the arguments of [2], and [3], the personalized requirement is recognized, and satisfied in the interacting co-design process which contributes to the product development. The second argument suggests that the touch-points are visualized by the co-design experience map in a virtual journey [4]-[7] that the touch-point is a contact point among consumers, retailers, and system online [8]. The third argument resides in the fact that design resources are integrated into the e-customized co-design map and are important for brand services [9]. It is concluded that the e-customized co-design product may be recorded via a virtual experience map, especially when design knowledge are not managed efficiently. Some difficulties may lie in co-design systems, which cause misunderstandings, require re-working, and result in additional time spent on the process.

There is a general lack of study on the exploration of design resources recommendation. The purposes of the study are (a) to identify the touch-points in co-design online, including nodes and main codes; (b) to propose a virtual experience map of online product co-design by using visualized data; and (c) to find the relationship between design categories and time spent. The paper is organized as follows. In the first section, the literature on evolutionary algorithm and fuzzy theory, co-design and virtual experience maps are reviewed. Furthermore, we outline a proposed method and introduce the framework of experience mapping and qualitative research. We then analyze and discuss the results. Finally, we conclude the current research.

\section{Theoretical background}

\subsection{Evolutionary Algorithm and Fuzzy Theory}

Evolutionary algorithm and fuzzy theory are applied in the apparel co-design system [28]. Design parameters are defined in the customized system for skirt design, that is supported by evolutionary algorithm [29]. Further, researchers proved that user-centered customization can be achieved in the product customization process and enhance the total profit, which empower the development of system development [30]. Meanwhile, the application of theory also contributes to the system application. There are also some findings that is supported by evolutionary algorithm and fuzzy theory, including the model of e-customized co-design system that improve the design knowledge recommendation and evaluation [31]. The design modular and/or information recommendation are supported by the relationship among categories in apparel e-customization system. Based on the above findings, evolutionary algorithm and fuzzy theory is adopted in the study of touchpoints that is supported by the relationship between time spending and design categories. 


\subsection{Co-design in Product Development}

Compared to the traditional shopping, more and more consumers tend to shop online, and who prefer to be involved into the product co-design process on internet, such as selecting colors, choosing fabrics, decorating and so on. Co-design is defined as the process of information sharing and co-generating new knowledge [2]. The co-design process is supported by all steps in the design process. With the support of technology development, online co-design is adopted by some companies (e.g., RedCollar, Nike ID, Vans) so as to meet consumers' personalized requirement. Co-design comprises the following factors: design culture; time constraints; design orientation; availability of communication and computer-supported systems [2]. Co-design reflects users' needs, goals, and desires, all of which contribute to the product development. Product creation is enhanced in co-design via integrating great ideas from other individuals and involving stakeholders in design.

Technical infrastructure is not a limitation to new product development, but organizing cooperation and communication among stakeholders is vital [10]. Co-design is accomplished by many individuals who notify each other via information sharing and decision making [11]. In co-design, users play a role as idea creators and, as Witell et al. [12] stated "organizations should be regarded as collaborative design contributors rather than passive agents". Thus, the interaction is an important part in co-design process. There are two kinds' interactions as user-system and user-stakeholders. Some researchers have found that the co-design interacting experiences begin with touch-points [2], [13]. Herd et al. [14], Marquez et al.[4], [5], and Thurgood et al. [15] proposed that touch-points are an approach for orienting users' needs in interaction. Researchers have studied designer cooperation and user feedback in case studies and have found that it is as difficult to evaluate the intangible outcomes from user interactions [16]. In this study, the touch-points is supported by the experience nodes and codes.

\subsection{Virtual Experience Map}

The experience map is a useful tool for human virtual activities. In analyzing knowledge, people's understanding is deepened by an experience map, which was supported by information flows that represent time, different learners, and information type [17]. The term "experience map" has been variously defined. The method of structured dialogic design delivered a map that was associated with the agreement of individuals' opinions and knowledge [18], [19]. Touch-points are key aspects of the product design experiences, researchers have indicated that touch-points were not in the same design orientation [14]. Thus, researchers found that the various touch-points were visualized by the map, which is a method to explain the steps and stages in task completion [4], [5]. Knowledge can be captured via experience map, that researchers obtain information related to design practice quality via monitoring and observing.

The user-centered service map was an effective tool to offer relevant services and new opportunities, though it required some support from the quantitative method [20]. There are three stages were included in the service procedure: constructing a potential needs dictionary, developing a service map, and identifying the service opportunities [13]. Thus, the authors suggest that the potential needs could be collected from users, which were mapped on the existing services. Vries and Masclet [21] stated that there were three ways to share information in co-design, such as a visual way of sharing; sharing the same tradition, which refers to the knowledge system; and matching interpretations. Users' stages could be visualized by the map, the users' behaviors are involved in design and service [4], [5]. Thus, users' behavior relates to 
design and service closely. The literature review supports the following sections of the virtual experience map and visualization of co-design touch-points.

\section{Methodology}

\subsection{Main Test Design}

The participants are involved with the NIKE iD e-customization website (http://store.nike.com/cn); components of the certain basketball shoe are displayed on interface. The participants are asked to select and match the color of these features freely who can use mobile phone and other social media tools to communicate with others. The results of the online co-design process are recorded by Screen Cap Expert V2014 and/or recorder. Then, the qualitative questions are answered by participants after they finish the virtual co-design experience. There is no time limitation.

\subsection{Measures}

The map is composed of two parts (i.e., touch-points and category), and the virtual co-design experience is recorded by time [4], [5], [13], [20]. Furthermore, based on the evolutionary algorithm and fuzzy theory, users' interactions in the online co-design website are represented by the vamp, heel, swoosh, lace, lace loops, lining, mid-sole, airbag, out-sole, long text, text and/or graphics. The data is coded and transcribed. The touch-points are filtered out by coding. Nodes are collected via creating a frequency query. According to the relationship between categories and time spent, the touchpoints is presented in the Equation 3.1. $\left(N_{1}, N_{2}, \ldots, N_{n}\right)$ presents the number of the participants, $f^{z}$ presents for which basketball shoes does the user select, $\left(C T_{1}, C T_{2}, \ldots, C T_{m}\right)$ presents for the categories. Meanwhile, $f^{x}$ presents for users' time spent in the virtual experiences, $\left\{\left(T S_{1}, T S_{2}, \ldots, T S_{k}\right)\right\}$ presents for the seconds spending in the co-design experiences.

$$
\text { Touchpoints }\left(N_{1}, N_{2}, \ldots, N_{n}\right)=f^{z}\left\{\left(C T_{1}, C T_{2}, \ldots, C T_{m}\right)\right\}+f^{x}\left\{\left(T S_{1}, T S_{2}, \ldots, T S_{k}\right)\right\}
$$

\subsection{Research process}

All participants are undergraduate students. The announcement is published by physical education department in the college. The test is taken in a visual art lab. A chocolate bar is provided to participants once they finished the test.

\subsubsection{Stage 1}

Before the test, participants are asked the following questions. (a) Have you ever bought Nike shoes online before? (b) Do you like Nike basketball shoes? (c) Have you ever co-designed? The five Likert scale is adopted in measurement, from " 1 = very disagree" to " $5=$ very agree". The demographic characters are also collected.

Table 1. Basic description of collected data

\begin{tabular}{|c|c|c|c|}
\hline Class & Question (a) & Question (b) & Question (c) \\
\hline \hline Mean & 4.3 & 4.1667 & 1.8667 \\
\hline Skewness & -1.014 & -.676 & .618 \\
\hline Kurtosis & .393 & -.474 & -.443 \\
\hline
\end{tabular}


8 female (26.67\%) and 22 male (73.33) participants are from a university for convenience. All participants aged between 19 and 22 years old. The value of skewness and kurtosis are between -2.0 and +2.0 , that means the variables have the normal distribution [22]. The question (c) shown that most of the participants did not co-design products before. Therefore, most of the participants are not familiar with the co-design system.

\subsubsection{Stage 2}

Participants are asked to perform the following steps in a lab room. The lab PC is available to them. Before performing virtual co-design experiences, the participants are asked to skim the website and scan the menu for five minutes, so as to familiar with the co-design system. The procedures are as follows: (a) Surfing on the brand website, and then, participants are asked to select the certain basketball shoes from a catalog. (b) They are asked to match the color according to their preferences. To facilitate a relaxed environment, there was no time limitation for participants. (c) The last step is to submit the customized shoes to shopping carts. The process is recorded.

\subsubsection{Stage 3}

In order to collect data from virtual experiences, questions of (a) how do you explore design problems; and (b) how do you solve the problems? are presented to participants after their experiences finished. The data is collected. The map is made by researchers that are based on the data collections.

\section{Results and discussion}

\subsection{General Description}

A total of 30 valid participants participated in the test. In the virtual experience map, the vamp and mid-sole are the two most time-consuming components, and the details of the lining and lace loops are the two least ones. In the after-experience qualitative study, more attention is drawn by selecting and exterior color matching. Furthermore, the feedback is shown in the visualized experience map, and some ideas are collected about the co-design interface.

\subsection{Virtual Experience Map}

As shown in Fig. 1, time spent is recorded in seconds. x axis presents for time spent, y axis presents for category. The two most upper limits of the categories are vamp (max $84 \mathrm{~s}$ ) and mid-sole ( $\max 73 \mathrm{~s}$ ), and two low limits ones are swoosh $(\min 3 \mathrm{~s})$ and heel $(\min 4 \mathrm{~s}$ ). The two long class width are vamp (span $78 \mathrm{~s}$ ) and mid-sole (span $59 \mathrm{~s}$ ), the two short ones are lining (span 22 s) and lace loops (span 24 s). 


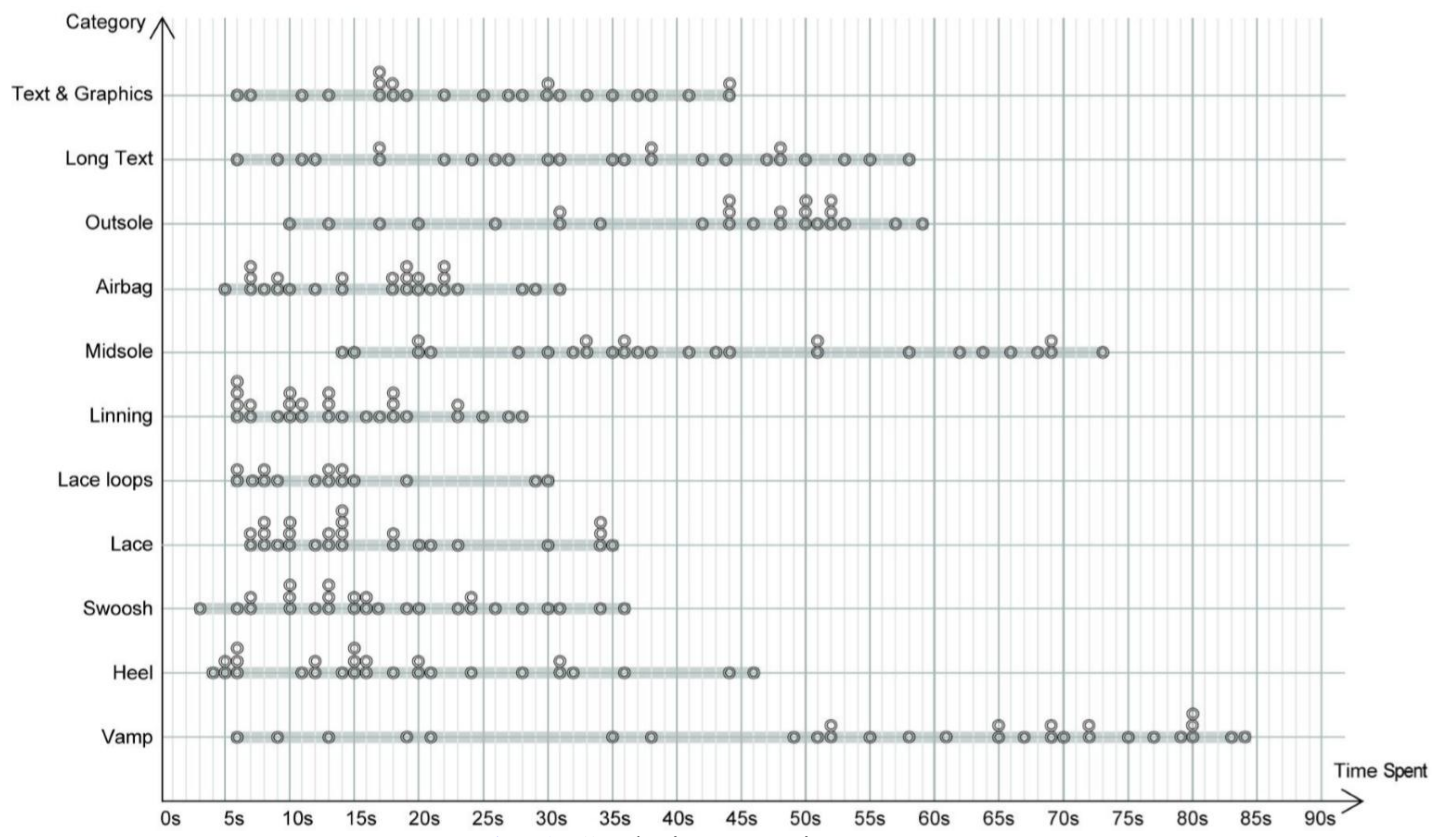

Fig. 1. Co-design experiences map.

The findings show that the time spent on design details indicate important potential requirements and show that the vamp color matching that takes a long span of time, which is consistent with the interview data and the previous findings [20]. However, our results suggest that the virtual experience map is represented by touch-points and tracks, which is different from previous studies [20] that organized the map as a hierarchical structure. Marquez et al.'s findings [4], [5] are supported by the mapping method. Meanwhile, participants state that it is difficult to select a color without professional help, which is demonstrated in the time spent of exterior design. We emphasize that participants are interested in basketball shoes' appearance, which is consistent with a previous study that the most important determinant for consumers is the product design [23]. Our results suggest that the color influence the participants' virtual perception. Previous studies have found that the product exterior appearance affects the quality of users' lives as these details exhibit long-lasting effects [24]. We find some similarity with a previous study in which the time spent are reflections of users' needs [25].

However, there are some limitations in this study. The co-design application of the virtual experience map is limited by its framework and the recording approach. Although the co-design orientation and the special requirements of users are revealed in the experience map, the brand product is a limitation of the experience map study because the map did not reflect the detailed experiences of users' emotions. In the step of the catalog review, the study proves that participants hesitate and waste much time; users' self-decision process indicate that there are some underlying and potential disadvantages in the co-design system which cannot be seen in the operating process. To some extent, this finding presents a possible approach for users to make decisions in future. Participants could communicate with others on mobile phone, but none of them did. This finding further indicates that there is still need system improvement on the interaction that users are encouraged to join in the design process with other team members online. The experience map showed the online co-design process, but why participants spend so much time on specific details are not explained. This also represents a limitation of the experience map study. Additionally, there are some limitations on the adopted theory of 
evolutionary algorithm and fuzzy theory. The further study should consider to involve the method of multi-objective optimization algorithm and hypercube optimization algorithm, so as to improve the quality of experiences [32], [33], [34].

\subsection{Qualitative Results}

The NVivo is adopted in the data analysis. The three-steps of coding approach are adopted in investigating the nodes and constructs (see Table 2). The word cloud is supported by the weight of nodes and codes (see Fig. 2). The users' experiences were a decisive factor, and users are given opportunities to create ideas for further services [26]. More potential service requirements from users are found in our qualitative research.

Table 2. Parts of nodes and main codes.

\begin{tabular}{|c|c|c|c|}
\hline Nodes & Accumulation & Weight $(\%)$ & Main Codes \\
\hline Color & 39 & 5.06 & color, colors, color, colors, dark \\
\hline Skewness & 31 & 4.02 & shoe, shoes \\
\hline Kurtosis & 22 & 2.85 & system \\
\hline Selection & 24 & 2.79 & $\begin{array}{l}\text { choose, options, pick, select, selecting, } \\
\text { selection, takes }\end{array}$ \\
\hline Function & 31 & 2.27 & $\begin{array}{l}\text { function, official, operate, operating, } \\
\text { operation, operational, run, useful, work, } \\
\text { works }\end{array}$ \\
\hline Matching & 20 & 2.12 & $\begin{array}{l}\text { check, fit, match, matched, matching, } \\
\text { touch }\end{array}$ \\
\hline Interface & 12 & 1.56 & interface \\
\hline Screen & 15 & 1.76 & screen, show, view \\
\hline Style & 10 & 1.23 & fashion, style, styles, trend, trends \\
\hline Operation & 19 & 1.17 & $\begin{array}{l}\text { operate, operating, operation, operational, } \\
\text { process, run }\end{array}$ \\
\hline details & 8 & 1.04 & detailed, details, items \\
\hline recommend & 8 & 1.04 & $\begin{array}{l}\text { recommend, recommendation, } \\
\text { recommended }\end{array}$ \\
\hline
\end{tabular}




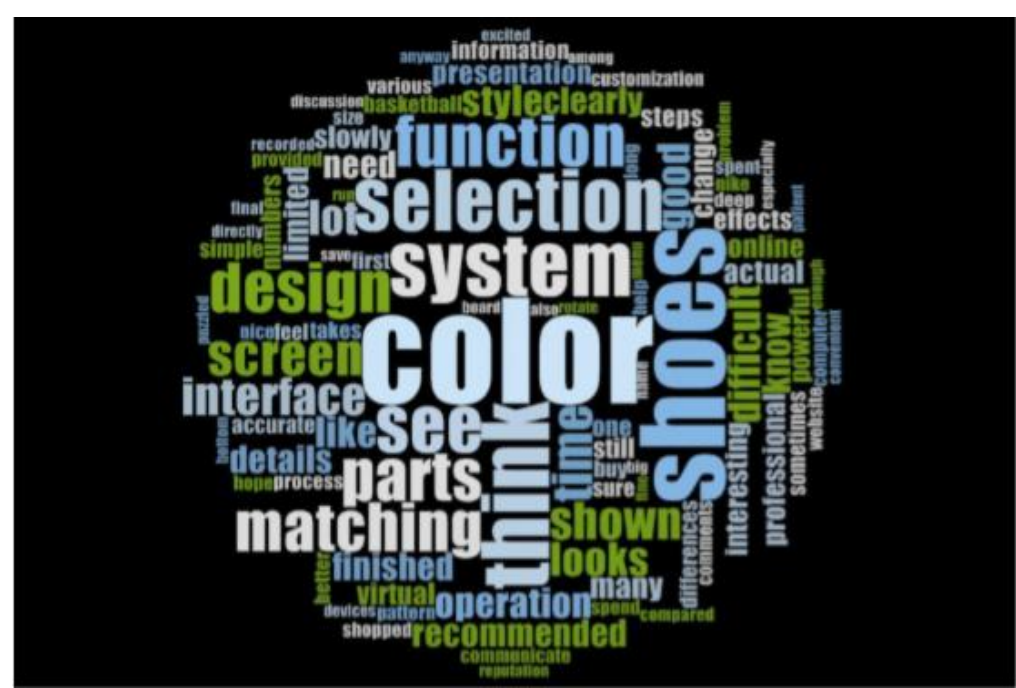

Fig. 2. Nodes and Codes in Word Clouds.

The results show that the color match, details selection, and function are the details that may create difficulties for participants. The results of a vamp and exterior color matching are proved in the feedback, which influences customer attitude directly. For instance, a participant's comments on the steps of color selecting and matching:

"I have some difficulties in selecting the vamp. The recommended color options are limited, and it is difficult for me to match colors. When I choose a color, somehow, I change it a few times. Then, I think the first color-matching effect is best. They are not recorded, so I cannot find them. I have to rematch colors as I remembered. If there were some recording tool or tracking steps in menu, it would be better ... [No. 3]"

Two other participants also describe the color matching. They state that:

"I am attracted by various styles online. I can select the color. It is exciting. There are so many recommended colors, which puzzled me. I spend much time on color matching. However, it is hard for me to choose which ones are perfect. I think I really need some professional help ... [No. 4]"

"I spend a lot of time on color matching for the vamp. When I change one color, I like to revise other colors so as to check if they are matched or not ... [No. 11]"

Furthermore, the material and style are highly influential experiences. For instance:

"The shoes look good. I like to touch materials, but I cannot do it on the screen. Some dark colors are the same as each other on a computer screen. I select a color from the recommended menu, but I am not sure whether it will be fit or not. The color and style are important to me. If the detailed parts and colors have been shown with a score, it would be easy for me ... [No. 24]"

Furthermore, the participants begin to realize their needs in the interface and function. Another salient finding is that participants give some suggestions on co-design interface, such as fashion trend recommendation, steps taken and presenting scenarios, all of which will affect the co-design services. The following two participants indicate their opinions as follows.

"It is difficult to imagine the effects of details with color matching. I think it would be convenient and efficient with some recommended fashion trends if related information is provided to me first. In fact, I do not like communicating with others on phone ... [No. 21]" 
"I do not like the virtual co-design system, as there is no discussion or communication board. Sometimes, I feel aimless with so many items... [No. 9]"

Another participant suggested that the final shoe is shown in a recommended scenario, which will be useful for him, as follows.

"I like to design basketball shoes online. The virtual system is useful and saves time. It works well on the final screen show. I like it. Compared to the shopping website, I hope that I could check the finished basketball shoes in a scenario rather than on a plain virtual background. I think it is unmatched. Sometimes, the virtual platform works slowly... [No. 13]"

However, another participant states that he is puzzled by the operating process. For instance:

"It is interesting for me to experience co-design basket shoes online. I view the shoes from different angles virtually. I am troubled that no sufficient instruction is provided on the co-design system. I am also puzzled about how many steps are remained. No schedule of steps is shown to me ... [No. 7]"

After analysis the collected data, the findings present that participants pay attention to the design elements, interface, online operation, recommendation, and process experiences that show why they have spent a long time in the process.

Our results indicated that the online co-design system supports users to solve problems according to their needs, which is consistent with previous findings from [18]. In this study, it is found that the categorized details were important in design knowledge management. This is consistent with previous studies with regard to the relation between user knowledge and unmet needs [27]. The results of the qualitative feedback showed that the virtual experience map played an important role in the co-design process which was examined in the qualitative research of user-centered service maps conducted by [20]. Even though it is useful to pass design knowledge to users in the interface, we would not be surprised to see the positive influence on the selection of lining, lace loops, and airbag. In the qualitative research, the participants showed their attention mainly on color matching, selection, interface, function, and operation.

The limitation lies in the number of products and categories. On the brand's website, the recommended category is mainly on colors and patterns rather than user-centered shapely co-design. Furthermore, the lack of professional online help in selecting design details was demonstrated from feedback. As the co-design process was composed of different factors, more studies are needed on detailed recommendation approaches.

We found that users need some professional information on color matching and design knowledge in the interface, which is consistent with the previous study [9]. Following the concept of co-design, users' behaviors showed a potential feedback. The framework reveals the relationship between users' needs and the information recommended by brand. Koutsabasis et al. [16] found that the requirement increased users' destinations and orientations, which is consistent with our findings. We also find that the benefits of the experience map were to assist team members via visualized communication and to encourage the adoption of fashion products by users. Our findings are consistent with the previous study in that the most innovative approach was related to users overcoming problems using their own creativity [27]. This finding might guide the users to provide and communicate detailed information, which has been established in the study of [13]. This approach would detect users' desires in communication and identify their requirements in each stage accurately. The online co-design map collected the data and supported previous studies on action and behavior 
reflection. These results are in accordance with [21], who concluded that identical meaning interpretation was an approach of co-design.

A limitation of this study is related to the results of the experience map and users' feedback, which are insufficient to reflect users' needs in online co-design interface owing to the different category of basketball shoe style. For example, some basketball shoes do not have laces. The participants are also limited in number. There is no comparison between different groups and genders. The feedback showed some potential explanation for the experience maps. Further studies on touch-points and the experience map evaluation need to be enhanced.

\section{Conclusion}

Our results indicate that vamp color-matching is consistent with interview data. Furthermore, supported by qualitative feedback, the virtual experience map played an important role in the co-design interface and visualized the interacting process. Consistent with prior research, participants prefer to get more information and professional instant help on color matching and exterior detail design. The findings prove that the virtual experience map served as a tool to support user-centered co-design showed that the time spent and category are organized by touch-points in the framework. The user-centered co-design inclination is indicated on the experience map.

The results of the study indicate that technological innovations have a significant impact on shopping approach and daily life. The results from the study show that the online co-design interface created a new generation of product development, which overcomes the limitation of certain individual role. It also shifts the online shopping to participate design via involving stakeholders in the co-design interface. Furthermore, it provides an opportunity to share information in the design process. The assessment of online co-design tracking is an approach to orient users' requirements in the design process. These results suggest that the application of virtual experience tracking and mapping contribute to enhancing the quality of online co-design services.

\subsection{Contribution}

This paper enriches the findings in algorithm logic and fuzzy theory. Virtual experience map is supported by the data analysis and provided a method to assess users' attitudes and interests in online co-design, including the touch-points that related to time spent and design categories. This study showed that the potential enhancement of the co-design service is found in the virtual experience map. Regarding managerial implications, the brand managers would develop a user-centered virtual experiences map based on this study. The service is assessed in the design categories and computer screen tracking, and the results are analyzed in qualitative research. Furthermore, the user-centered study is a direct reaction to the supply chain endings. Accordingly, the user experience is not only the domain of marketing departments but is also related to stakeholders. The experience map and data analysis indicate the reliable design resources for users. In this situation, the impact of the co-design system could be expanded to multidisciplinary communication.

\subsection{Future studies}

Future studies should explore developing these approaches and realizing a detailed map of online co-design services are aimed at users' emotional needs. Good experiences should be constructed between stakeholders with communication to offer visualized information to users 
rather than narrative recommendations and graphic design resources. Finally, professional services should be available to users, whenever they needed. For example, the online communication board should be developed to prescribe and forecast users' need and could be updated by following their characteristics. We expect our research in this area will directly enhance user satisfaction with brand design activities and services; certainly, the brand value would be significantly improved.

\section{References}

[1] M.-L. Chiu, "An organizational view of design communication in design collaboration," Des. Stud., vol. 23, no. 2, pp. 187-210, 2002. Article (CrossRef Link).

[2] M.-L. Chiu, S. Yamaguchi, and M. Morozumi, "Supporting collaborative design studios-scenarios and tools," Comput. Archit. Des. Res. Asia, pp. 125-134, 2001. Article (CrossRef Link).

[3] U.-J. Yu and J. Park, "Consumers' Virtual Product Experiences and Risk Perceptions of Product Performance in the Online Co-Design Practice: A Case of NIKEiD," Fam. Consum. Sci. Res. J., vol. 43, no. 1, pp. 29-46, 2014. Article (CrossRef Link).

[4] J. Marquez and A. Downey, "Service design: toward a holistic assessment of the library Services," PNLA Q., vol. 80, no. 1, 2015. Article (CrossRef Link).

[5] J. J. Marquez, A. Downey, and R. Clement, "Walking a mile in the user's shoes: Customer journey mapping as a method to understanding the user experience," Internet Ref. Serv. Q., vol. 20, no. 3-4, pp. 135-150, 2015. Article (CrossRef Link).

[6] J. D. Novak and A. J. Cañas, "The origins of the concept mapping tool and the continuing evolution of the tool," Inf. Vis., vol. 5, no. 3, pp. 175-184, 2006. Article (CrossRef Link).

[7] C. R. Wilkinson and A. De Angeli, "Applying user centred and participatory design approaches to commercial product development," Des. Stud., vol. 35, no. 6, pp. 614-631, 2014. Article (CrossRef Link).

[8] S. Baxendale, E. K. Macdonald, and H. N. Wilson, "The impact of different touchpoints on brand consideration," J. Retail., vol. 91, no. 2, pp. 235-253, 2015. Article (CrossRef Link).

[9] P. Holimchayachotikul, R. Derrouiche, D. Damand, and K. Leksakul, "Value creation through collaborative supply chain: holistic performance enhancement road map," Prod. Plan. Control, vol. 25, no. 11, pp. 912-922, 2014. Article (CrossRef Link).

[10] B. Yenicioglu and A. Suerdem, "Participatory new product development--a framework for deliberately collaborative and continuous innovation design," Procedia-Social Behav. Sci., vol. 195, pp. 1443-1452, 2015. Article (CrossRef Link).

[11] L. Wang, W. Shen, H. Xie, J. Neelamkavil, and A. Pardasani, "Collaborative conceptual design? state of the art and future trends," Comput. Des., vol. 34, no. 13, pp. 981-996, 2002. Article (CrossRef Link).

[12] R. Verma, A. Gustafsson, P. Kristensson, and L. Witell, "Customer co-creation in service innovation: a matter of communication?," J. Serv. Manag., vol. 23, no. 3, pp. 311-327, 2012. Article (CrossRef Link).

[13] J. Kim and Y. Park, "Identifying a new service opportunity from potential needs: User-centric service map," in Proc. of 2010 IEEE International Conference on Industrial Engineering and Engineering Management, pp. 357-361, 2010. Article (CrossRef Link).

[14] K. Herd, A. Bardill, and M. Karamanoglu, "Designing for co-design: using the product envelope model as a framework for reflection," in Proc. of World Conference on Mass Customization \& Personalization, Cambrige, USA, 2007. Article (CrossRef Link).

[15] C. Thurgood, M. O'Donnell, G. Peppou, R. Lulham, and S. Bucolo, "A Tool to Bridge Design Innovation Research and Practice: The Project Experience Map," in Proc. of Academic Design Management Conference, 2016. Article (CrossRef Link).

[16] P. Koutsabasis, S. Vosinakis, K. Malisova, and N. Paparounas, "On the value of virtual worlds for collaborative design,” Des. Stud., vol. 33, no. 4, pp. 357-390, 2012. Article (CrossRef Link). 
[17] L. Zheng, R. Huang, G.-J. Hwang, and K. Yang, "Measuring Knowledge Elaboration Based on a Computer-Assisted Knowledge Map Analytical Approach to Collaborative Learning.," Educ. Technol. Soc., vol. 18, no. 1, pp. 321-336, 2015.

[18] Y. Lee and S. Park, "Design of a Government Collaboration Service Map by Big Data Analytics," Procedia Comput. Sci., vol. 91, pp. 751-760, 2016. Article (CrossRef Link).

[19] K. Weigand, T. Flanagan, K. Dye, and P. Jones, "Collaborative foresight: Complementing long-horizon strategic planning," Technol. Forecast. Soc. Change, vol. 85, pp. 134-152, 2014. Article (CrossRef Link).

[20] J. Kim, S. Lee, and Y. Park, "User-centric service map for identifying new service opportunities from potential needs: A case of app store applications," Creat. Innov. Manag., vol. 22, no. 3, pp. 241-264, 2013. Article (CrossRef Link).

[21] E. De Vries and C. Masclet, "A framework for the study of external representations in collaborative design settings,” Int. J. Hum. Comput. Stud., vol. 71, no. 1, pp. 46-58, 2013. Article (CrossRef Link).

[22] P. Mallery and D. George, SPSS for Windows step by step: a simple guide and reference, Allyn, Bacon, Boston, 2003. Article (CrossRef Link).

[23] R. G. Cooper and E. J. Kleinschmidt, "New products: what separates winners from losers?," $J$. Prod. Innov. Manag., vol. 4, no. 3, pp. 169-184, 1987. Article (CrossRef Link).

[24] P. H. Bloch, "Seeking the ideal form: Product design and consumer response," J. Mark., vol. 59, no. 3, pp. 16-29, 1995. Article (CrossRef Link).

[25] E. Arias, H. Eden, G. Fischer, A. Gorman, and E. Scharff, "Transcending the individual human mind? creating shared understanding through collaborative design," ACM Trans. Comput. Interact., vol. 7, no. 1, pp. 84-113, 2000. Article (CrossRef Link).

[26] P. Kristensson and P. R. Magnusson, "Tuning users' innovativeness during ideation," Creat. Innov. Manag., vol. 19, no. 2, pp. 147-159, 2010. Article (CrossRef Link).

[27] P. Duverger, "Variety is the spice of innovation: mediating factors in the service idea generation process," Creat. Innov. Manag., vol. 21, no. 1, pp. 106-119, 2012. Article (CrossRef Link).

[28] R. Nayak and R. Padhye, "Artificial intelligence and its application in the apparel industry," Automation in Garment Manufacturing, The Textile Institute Book Series, pp. 109-138, 2018. Article (CrossRef Link).

[29] P.Y Mok,. Xu, J., and Wu, Y.Y, "Fashion design using evolutionary algorithms and fuzze set theory - a case to realize skirt design customizations," Information Systems for the Fashion and Apparel Industry, pp. 163-196, 2016. Article (CrossRef Link).

[30] Xu, Y., Landon, Y., Segonds, S., and Zhang, Y, "A decision support model in mass customization," Computers \& Industrial Engineering, vol. 114, pp.11-21, 2017. Article (CrossRef Link).

[31] Li, P., and Chen, J.H., "A model of an e-customized co-desgn system on garment design," International Journal of Clothing Science and Technology, vol. 30, no. 5, pp. 628-640, 2018. Article (CrossRef Link).

[32] J. Huang, L. Xu, C. Xing, and Q. Duan, “A Novel Bio-inspired Multi-objective Optimization Algorithm for Designing Wireless Sensor Networks in the Internet of Things," Journal of Sensors, Vol. 2015, Article ID 192194, 16pages, 2015. Article (CrossRef Link).

[33] J. Huang, X. Huang, Y. Ma, and Y. Liu, "High-dimensional objective optimizer: An evolutionary algorithm and its nonlinear analysis," Expert Systems with Applications, vol. 38, no. 7, pp. 8921-8928, July. 2011. Article (CrossRef Link).

[34] J. Huang and Y. Liu, "MOEAQ: A QoS-Aware Multicast Routing Algorithm for MANET," Expert Systems with Applications, vol. 37, no. 2, pp. 1391-1399, Mar. 2010. Article (CrossRef Link). 


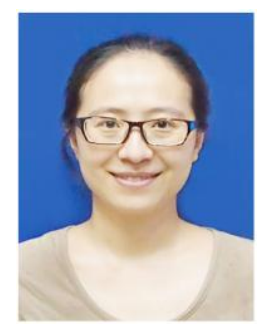

Pei Li: She received the B.A. degree in Fashion Design and Engineering from Shandong University of Art and Design, China, in 2006, M.A. degree and Ph.D. degree in Fashion Design and Engineering from Donghua University, Shanghai, China, in 2009 and 2019, respectively. She is currently an Associate Professor in the School of Textiles and Fashion, Shanghai University of Engineering Science. She is interested in User Experiences, Behavior, Multisensory Perception, E-customization etc.

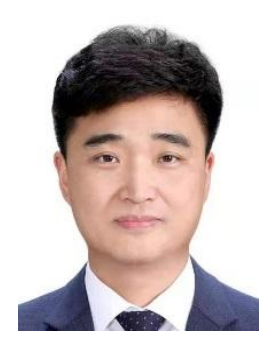

Ziyang Liu: He received the B.A. degree in Management from the Institute of Army Staff Officer of the PLA, China, in 2006, M.A. degree and Ph.D. degree in Management from Kyonggi University, Korea, in 2010 and 2013, respectively. He is currently an Assistant Professor in the Global Business Kyonggi University. He is interested in Quality Management. Management Information Systems, International economics, E-customization etc. 